\title{
Exploring Research and Innovation in Engineering Education in African Higher Education
}

\author{
Dr. Kehdinga George Formunyam \\ Teaching and Learning Development Centre, \\ Mangosuthu University of Technology, \\ South Africa. \\ Orcid id: 0000-0003-2510-3498.
}

\begin{abstract}
There has been a rapid increase in the global population in general and Africa in particular and this has made access to adequate housing, sufficiency in power, access to good roads and adequate access to health care very difficult on the African continent. As a result of this, there is a need to rethink sustainable economic growth and a better life for all. This can only be made possible through research and innovations. Research and innovation which explores all fields STEM fields particularly engineering and all its sub disciplines. Hence, this paper explored how engineering research can lead to innovations that will help solve the problem of socioeconomic inadequacies of Africa. The findings reveal that in a world shaped by a high degree of complexity, fluidity, and uncertainty, engineering education through research and innovation can provide a gateway to meet the constantly evolving need of mankind. The paper therefore recommends that governments in Africa need to invest more in engineering research as it remains a vital option to ensure growth and economic development on the continent. This can be done by creating a conducive atmosphere for research innovation and engagement, as well as constantly increasing funding for research and development along that line. Premiums should also be placed on universities and industries to work collaboratively to see the desire result.
\end{abstract}

Keywords: Research, innovation, engineering, engineering education,

\section{INTRODUCTION}

Africa as a continent is ravaged with by poor infrastructures that affects the quality of life. Basic infrastructures like housing, water, electricity, roads, hospitals and information, and communication technologies, are missing in most countries in Africa. It is believed that about one billion people do not have access to clean water globally (Lewis, 2010). And a majority of these people living in Africa. Therefore, there are limited sources of water available to provide clean drinking water to the entire population of Africa. More so, housing in African remains a huge problem. According to Bah, Faye and Geh (2018) owning a decent house is still an unattainable goal for many African households. Bah et al., (2018) continue that the lack of affordable housing finance, high costs of urban land and weak tenure security, rising construction costs, and prevalence of slums are major challenges to efforts to alleviate the continent's housing crisis. Finding decent and affordable housing in Africa still remains out of reach to a lot of Africans and is affecting the quality of life of residents in the continent. Furthermore, electricity remains a recurring problem in Africa. There is good news about electricity globally, but bad news with regards to electricity in Africa. The good news is that the number of people without access to electricity globally has dropped, from 1.2 billion in 2010 to 840 million in 2017 . While the report predicts that by 2030, there will still be about 650 million people without access to electricity, and 9 out of 10 of them will live in Sub-Saharan Africa (Odarno, 2019). This prediction is worrisome, which means Africa needs to respond swiftly to ensure that this prediction is averted. Transportation is another major challenge on the African continent. Dahir (2107) argues that a distinct feature of African cities is that they continue to be crowded, with unreliable transport networks and snarling traffic jams. Dahir continues that unlike many other parts of the world, the African continent has lower road density and quality, with bad maintenance of roads causing accidents that kill the greatest number of people anywhere in the world. The shocking thing to note is that there are not enough funds made available by governments in Africa to ensure new roads networks are built to ease transportation and quality of life. Furthermore, the quality of the health sector in Africa still leaves a lot to be desired. Statistically, about 1.6 million Africans died of malaria, tuberculosis and HIV-related illnesses in 2015. Pheage (2017) adds that these diseases can be prevented or treated with timely access to appropriate and affordable medicines, vaccines and other health services. However, the major problem is that less than $2 \%$ of drugs consumed in Africa are produced on the continent, meaning that it becomes very hard for sick Africans to easily have access to drugs, since most of the drugs are not produced locally, and most times are not financially buoyant to buy the imported drugs. Pheage (2017) continuous that the easy way out of this dilemma is to encourage the local production of drugs on the continent. All of the challenges listed above can be solved with investments in engineering education. Hence, this paper proposes investment in engineering research as a viable solution to these problems bedeviling the growth of the African continent. More investments in engineering research will lead 
invariably to innovations that are local to the African environment and thus poses as a solution to the problem of poor transport networks, poor health infrastructure, inadequate housing and unclean water in the continent.

To this effect, this paper is divided into different sections. The first section introduces the challenges ravaging the continent, while the second explores engineering research and innovation. The third part explores challenges of engineering researching research in Africa. The fourth explores engineering research and innovation as a response to continental challenges and the last part of the paper is the conclusion.

\section{ENGINEERING RESEARCH AND INNOVATION}

Artigue and Perrin-Glorian (1991) defines engineering research as research that seeks improvements in theory and practice in different fields of life, such as high-speed computation, bioengineering, earthquake prediction, power systems, nanotechnology and construction amongst others. This means that engineering education and by extension engineering research can be said to play important roles in ensuring economic growth and development. White (1995) stated that engineering research is helping to achieve economic growth and development to an increasing degree as more technically advanced and complex products and systems are emerging in the marketplace and in the social and economic infrastructure. Engineering research helps in the design of new products and technology. Engineering research always takes different forms, as it largely depends on the branch of engineering where the research work is being done, as well as the industry in which the research work covers. According to Learn.org (n.d.), research engineers with backgrounds in mechanical engineering may work in the fields of product development and industrial design, while, trained engineers in electrical engineering may work in hardware or software development. Furthermore, they stated that bioengineering research, as a branch of engineering education may be useful for developing medical technology; aerospace engineers develop space technology. Some other research engineers develop because of their research to develop optical systems, and others work with heating and thermodynamic systems, while some work to make cars safer, and others find ways to improve equipment and machinery used in hospitals. Based on this analogy, it is clear that engineering research covers a wide range of human life and that the result of engineering education helps improve the quality of life. Lockhart (n.d) related that the aim of engineering research is to improve the current technologies offered by organisations or to develop innovations that strengthen an organisation's position in the marketplace or develop innovations to make living much easier. More investment in engineering research in Africa, will produce meaningful solutions to the challenges facing the continent.

Innovation on the other hand has its roots in the Latin word Innovare which means to make something new (Amidon, 2003). This means that innovation means a drive to make something better. Innovation is a broad term used in many disciplines, and it is described as a new way of proffering solutions to a problem and doing things. This was explained further by Tidd, Bessant, and Pavitt (2002) who argued that innovation is all about change. Doyle (2002) added that innovation involves bringing an idea to user on a commercial level by having a change in processes, goods and services and the way it was created or delivered. O'Regan, Ghobadian, and Sims (2006) were of the opinion that innovation is a new approach to identifying what the needs of customers are. While Jobber (2001) on the other hand offered an alternative understanding by seeing it as what happens when a new idea is commercialized by taking it to the market. Kings and Anderson (2002) argued that innovation includes series of scientific, technological, organizational, financial and commercial activities and is delineated into three phases - problem identification and idea generation, gathering support and idea implementation. Camisón and Forés (2010) argue that innovation is the conversion of new or existing knowledge to value which can be made manifest in goods or services for the use of people, groups or society. It stems from knowledge acquired over time, and it is vital in developed and developing countries for proffering solutions to various challenges that are predominant there. Barton, Schlemer, and Vanasupa (2012) take this further by stating that innovation in engineering education can involve problem-solving, process improvement and transformation and this may lead to new products, processes, infrastructure, services or design that promotes human well-being, including gender equality, identify new markets and business opportunities, develop technologies that meet the needs of a complex and diverse user group and enhance global competitiveness and sustainability. To this end, there is the need to rethink business processes, production of goods and services and this can primarily be done through the lens of engineering education.

Since research and innovation are key in engineering education (Garcia-Penalvo, Johnson, Ribeiro, Minovic, \& CondeGonzalez (2014), investing in engineering education is one way of promoting research and innovation especially in Africa where most governments are yet to commit a significant percentage of their yearly budget on higher education. Most of the research and innovation being consumed in Africa today has been produced elsewhere. This may explain why most of the basic human infrastructures responsible for survival are still largely missing in Africa, because of the cost implications they incur when essential technologies are imported. Therefore, research and innovation in engineering education, are inseparable can be said to have a symbiotic relationship.

Investing in research and innovation in particular and by extension engineering education would empower engineering students to handle the complex challenges evolving as a result of changes in the social, economic, environmental and technical sphere, and some of these challenges have been tagged wicked problems because they are massively complex, uncertain and value-driven (Frame and Brown, 2008). As such, there is a vital need for students and lecturers to develop the capability to combat these problems from an engineering standpoint. This can be achieved in Africa by significantly increasing investments to engineering education with the aim of improving the quality of engineering education so that local innovations will be encouraged. Within the context of the fourth industrial revolution, future engineers are meant to be highly qualified in an attempt to remain relevant both in the 
now and in the future. For African students to become credible leaders in engineering education and hence engineering innovation, qualitative engineering research is pertinent, and this can only be made possible with more investments in engineering education in Africa. There is also a nexus between research, innovation and the capability to solve societal and organizational problems. To deal with the complex anticipated organizational and societal problems, there is a need for engineers to learn new ways of approaching and solving these problems, necessitating the need for more investments in engineering education in the African continent (GarciaPenalvo, Colomo-Palacios \& Lytras, 2012; Garcia-Penalvo et al, 2012)

\section{CHALLENGES OF ENGINEERING RESEARCH IN AFRICA}

Despite the importance of engineering research in bolstering engineering innovation, so many challenges still impede the growth of engineering research in Africa, thus, affecting the level of engineering innovation on the continent. This has made the continent dependent on engineering innovations from continents other than Africa, and this has greatly slowed the growth and development of the continent. First of all, it is important to note that Africa is not producing enough scholarly research with respect to engineering education. For example, Africa has only published 75,157 engineering scholarly articles in the past 20 years, while regions like Western Europe and Northern America have published more than 1,500,000 in the past 20 years (Patra, 2017). This clearly depicts the fact engineering research in Africa is still significantly lacking behind other continents in the world, and this explains why there are extremely few engineering innovations in the continent. However, why are Africans not producing enough when it comes to engineering research?

The challenges of engineering research in Africa can be categorized into three categories: supervisor related challenges; student-related challenges and institution-related challenges. According to Thomas and Nelson (2001), supervisor related challenges in Africa with special reference to engineering education includes, the fact that most often supervisors do not have regular contact with the students; supervisors always have lackadaisical attitude toward students' interest in a particular topic. They continue that some supervisors do not give enough practical assistance to students, while others give inadequate direction to the students. At other times, some supervisors take longer than necessary to provide students with the required feedback while others who are willing to provide support the experience, skills, and knowledge, in some of the vital areas often needed by students (Thomas \& Nelson, 2001). All of these supervisor-related challenges put together are expected to slow the progress of engineering education, invariably not making African engineers highly innovative in the discharge of their duties. Mapolisa and Mafa (2012) speaking on studentsrelated factors posit that some of the challenges affecting research and innovation in engineering education are student related. They argue that these factors include: students not having ample time for research, lack of funds to finance research, inability of some students to source required information from the internet, inadequate information obtained from the library facilities, some students lack competence and research motivation, some students' lack of theoretical background in the area of research and family challenges and commitments. This means that the reasons for the poverty of research and innovation in engineering education are numerous and require a complex approach to engage. Students are not motivated to carry out ground-breaking research and are always searching for ways to cut corners with research work. Mnguni (2019) adds that some students are not concerned about the novelty of their research work, or about the contribution of their research work to the body of knowledge but are primarily concerned about getting their research work approved. This calls for a change, a change that will entice and induce students to engage themselves in researches that will change their immediate environment for the better. Governments also need to do more in terms of making funds available to students, as engineering research can be cost-intensive. Having readily available funds for students to use will tempt students to carry out important researches that are necessary to solve imminent societal problems. Furthermore, Thondhlana, Mawere, and Weda (2011) discoursed institution-related challenges that have affected the growth of engineering research in Africa. They pointed out that the major institutional related challenges in Africa to engineering education is the issue of lack resource materials needed for research as well as internet connectivity. Research is largely dependent on the resources made available by the institution from libraries to workshops amongst others. Students may become stressed out as a result of inadequate resources. This greatly and significantly reduces the quality of research carried out by students. More so, most institutions in Africa hardly have efficient connectivity to the internet. Research nowadays largely depend on the connectivity, and with a lack of quality internet in African Universities, there is always bound to be inadequate research and innovation in engineering education on the continent.

\section{ENGINEERING RESEARCH AND INNOVATION AS A RESPONSE TO CONTINENTAL CHALLENGES}

Iwuoha (2017) argue that in many parts of Africa, 85\% of roads are unusable during the wet season, and even at the current level of investment to improve the continent's road infrastructure, estimates show it could take Africa up to 50 years to catch up with the developed world. This has affected the movement of goods and services to rural areas and hence limits the standard of living for people. However, the cost of improving African transport infrastructure to meet that of the developed world is beyond what the continent can handle at the moment. Furthermore, the construction of such roads as have been seen in the past have been without challenges. Matthews (2018) argued that building new roads across sub-Saharan Africa often changes the landscape, bringing dust, flooding, and erosion. Matthews continues that the impact is felt most by rural communities. Roads can negatively affect water flows to wetlands, block fish movements and cause landslides, as well as impact the livelihoods of millions of people. Such situations therefore require engagement by researchers in engineering education to develop innovative ways which will not only reduce the cost of road construction on the government, but also 
on the environment and the people living in the communities around which these roads are being constructed. Significant reduction in the cost of road construction will make it easier for governments in Africa to repair all bad roads and improve road networks in the country. More so, as earlier affirmed, the current technology used in road construction is abrasive to human existence, therefore, it needs upgrading. Engineering research can respond to these as a way of ensuring that the continent catches up with the rest of the world.

Africa is also heavily characterized by inadequate housing. This is because more than twenty percent of people in Africa live in slumps and this evidently expose them to insecurity caused by overcrowding, poor sanitation and high rates of crime. This is confirmed by Bah et al., (2018), who argue that 17 African countries have housing deficits of more than 1 million units and if nothing is done to dramatically change the situation, poor urban planning and inadequate housing supply will severely constrain Africa's structural transformation. Africa is believed to be entering a housing crisis, as demand for housing significantly overweighs housing supply. This has been exacerbated by the daily migration from rural areas to urban centers. Estimates according to Otieno (2015) suggests that by 2050 Africa's population will have doubled reaching 2.4 billion which will stretch the cities to beyond breaking point due to inadequate housing and associated infrastructure. Specifically speaking, Egypt has a housing deficit estimated conservatively at 3.5 million, Nigeria, Africa's most populous country has a housing deficit of about 17 million houses, and Kenya approximately has a housing deficit of more than 2 million houses (Otieno, 2015). These figures show the everincreasing housing demands and deficit in Africa. One of the major reasons for this deficit is the high cost of building materials on the continent, making it extremely difficult for governments to financially meet their housing obligations. A viable solution to inadequate housing and deficit in Africa is for governments in Africa to invest heavily in engineering research, mandating engineers on the continent to find new methods of building houses local to the continent that will cost far less than the current methods used. Investments in this regard will make it easier to reduce the housing deficits on the continent, by ensuring innovative ideas with more rigorous research in engineering education made possible by more investments in the discipline of engineering.

Kirigia and Barry (2008) argue that Africa is plague by numerous health challenges result from inadequate health care facilities, and medical personnel to provide medical solutions on the continent. They argue for example that

Out of 58.03 million people who died globally in 2005, 10.9 million (18.8\%) were from the African Region. Majority of deaths $(64 \%)$ that occurred in the Region resulted from HIV/AIDS (19\%), lower respiratory infections (10\%), malaria $(8 \%)$, diarrhoeal diseases $(7 \%)$, cerebrovascular disease $(4 \%)$, ischaemic heart disease $(3 \%)$, tuberculosis $(3 \%)$, measles $(3 \%)$, low birth weight $(2 \%)$, birth asphyxia and birth trauma $(2 \%)$ and maternal conditions (2\%). Even though effective public health interventions that could have prevented most of deaths exist, coverage is low due to weak and under-resourced health systems. Some of the weaknesses can be attributed to challenges related to leadership and governance; health workforce; medical products, vaccines and technologies; information; financing; and services delivery" (Kirigia \& Barry, 2008, p. 1).

Primary health centres in most cases do not have basic drugs and injections to treat common sicknesses and diseases. This is because drugs and injections are always very expensive in these areas especially because most of these drugs are imported. McIntyre, Obse, Barasa and Ataguba (2018) argue that to solve this problem, Africa needs to become producers of drugs and injections, but this can only be made possible if there are necessary equipment. In this case, investments need to be made in engineering education to ensure the production of machines which would then be used in producing these drugs and injections. This will significantly reduce the cost of drugs and injections in Africa. Thereby, making it possible for drugs to be readily available in all nooks and crannies of the African continent. Kirigia and Barry (2008) conclude that

Effective public health interventions are available to curb the heavy disease burden in Africa. Unfortunately, health systems are too weak to efficiently and equitably deliver those interventions to people who need them, when and where needed. Fortunately, the health policymakers know what actions ought to be implemented to strengthen health systems. However, it might not be possible to adequately implement those actions without a concerted and coordinated fight against corruption, sustained domestic and external investment in social sectors (e.g. health, education, water, sanitation), and enabling macroeconomic and political (i.e. internally secure) environment (Kirigia \& Barry, 2008, p. 8).

All the above-mentioned areas, a space in which engineering research and innovation can rightly step in to provide the needed support if appropriate funding is provided. Ngongalah, Niba, Wepngong, and Musisi (2018, p. 1) argue that the ability to conduct and produce high-quality research in Africa was seen to be influenced by multiple factors, most of which were related to the funding and research environment in African countries. Priority areas for improvement included providing more training, raising awareness on the importance of research in Africa, encouraging governments to commit to research and increasing collaboration between researchers in Africa. With the numerous challenges plaguing the continent quality research in engineering education would provide valuable solutions to these challenges. As such, more investment is needed in the field of engineering research in Africa to ensure innovations in the region as well as ensuring that proffered solutions to African problems are contextually relevant. Achieving this feat in engineering research will put African innovations in engineering in the spotlight and may lead to the exportation of African innovations to other parts of the world.

\section{CONCLUSION}

Quality engineering research and innovation in Africa can be made possible by intensifying effort to increase the funding available for engineering education, as it remains a vital option to ensure growth and economic development for the nations in particular and the continent as a whole. It is therefore important 
that the government of countries in Africa look more specifically towards research and innovation in engineering education and support it more by improving investments in that regard. This can be done by creating a conducive atmosphere for research and innovation and by increasing funding for research and development along that line. Premium should also be placed on universities and industries to work hand in hand to ensure the research being produced within universities is valuable in the knowledge economy. The role of the university in research and innovation cannot be trivialized and they are necessary for the production of knowledge that culminates in the development and better standards of living. Therefore, more support and polices are needed to ensure that engineering research and innovation thrive well in universities in Africa, and by extension positively affect the growth of the economies in Africa.

\section{REFERENCES}

[1] Amidon, D. (2003). The Innovation Highway. Boston: Butterworth-Heinemann.

[2] Artigue, M., \& Perrin-Glorian, M. J. (1991). Didactic engineering, research and development tool: some theoretical problems linked to this duality. For the learning of Mathematics, 11(1), 13-18.

[3] Bah, E. M., Faye, I., \& Geh, Z. F. (2018). The housing sector in Africa: Setting the scene. Housing Market Dynamics in Africa, 1-21.

[4] Frame, D., \& Brown, J. (2008) Developing post-normal technologies for sustainability. Ecological Economics, 65(2), 225-241.

[5] Camisón C, \& Forés B (2010) Knowledge Absorptive Capacity: New Insights for its Conceptualization and Measurement. Journal of Business Research 63(7), 707715.

[6] Dahir, A. L. (2017). African countries still can't raise enough capital to replace their bad roads. Retrieved from https://qz.com/africa/945724/african-countries-still-cantraise-enough-capital-to-fix-their-poor-road-networks/ [Accessed on 15/01/2020].

[7] Doyle, P. (2002). Marketing Management and Strategy. 3rd ed., Harlow, Sussex: Pearson Education Ltd.

[8] Fayomi, O. S. I., Okokpujie, I. P., \& Kilanko, O. (2018). Challenges of research in contemporary Africa world. IOP Conference Series: Materials Science and Engineering. Retrieved from https://iopscience.iop.org/article/10.1088/1757899X/413/1/012078/pdf/ [Accessed on 15/01/2020].

[9] Garcia-Penalvo, F. J., Johnson, M., Ribeiro, G., Minovic, M., \& Conde-Gonzalez, M. A. (2014) Informal learning recognition through a cloud ecosystem, Future Generation Computer Systems, 32, 282-294.

[10] Garcia-Penalvo, F. J., Colomo-Palacios, R., \& Lytras, M. D. (2012) Informal learning in work environments. Training with the Social Web in the workplace, Behaviour \& Information Technology, 31(8), 753-755.

[11] Gendered Innovations (n.d.). Engineering innovation processes. $\quad$ Retrieved from https://genderedinnovations.stanford.edu/methods/innov ation.html/ [Accessed on 15/01/2020].

[12] Iwuoha, J. (2017). This interesting technology could replace all the bad roads in Africa. Retrieved from https://www.smallstarter.com/get-inspired/thisinteresting-technology-could-replace-all-the-bad-roadsin-africa/ [Accessed on 15/01/2020].

[13] Jobber, D. (2001). Principles and Practice of Marketing, 4th ed. Berkshire: McGraw-Hill International Ltd.

[14] King, N. \& N. Anderson. (2002). Managing innovation and change: A critical guide for organizations (2nd Ed.). London: Thomson.

[15] Kirigia, M. J., \& Barry, S. P. (2008). Health challenges in Africa and the way forward. International Archives of Medicine, 1, 27.

[16] Learn.org (n.d.). What are some of the job duties of a research engineer? Retrieved from https://learn.org/articles/What_are_Some_of_the_Job_D uties_of_a_Research_Engineer.html/ [Accessed on $15 / 01 / 2020]$.

[17] Lewis, L. (2010). Rural and urban water issues in Africa. Retrieved from https://thewaterproject.org/watercrisis/water-in-crisis-rural-urban-africa/ [Accessed on 13/01/2020].

[18] Lockhart, P. (n.d) Research and development (R\&D): industry sector overview. Retrieved from https://targetjobs.co.uk/careersectors/engineering/282475-research-and-developmentrd-industry-sector-overview/ [Accessed on 15/01/2020].

[19] Mapolisa, T., \& Mafa, O. (2012). Challenges being experienced by undergraduate students in conducting research in open and distance learning. International Journal of Asian Social Science, 2(10), 1672-1684.

[20] Matthews, N. (2018). A cheaper, innovative design structure could be the key to better roads in African countries. Retrieved from https://qz.com/africa/1446191 /how-to-avoid-flooded-roads-in-africa-with-betterdesign/ [Accessed on 15/01/2020].

[21] McIntyre, D., Obse, A. G., Barasa, E. W., \& Ataguba, J. E. (2018). Challenges in financing universal health coverage in sub-Saharan Africa. In Oxford Research Encyclopedia of Economics and Finance.

[22] Mnguni, L. (2019). The PhD quality debate has racist tones. Mail \& Guardian 29 November 2019 https://mg.co.za/article/2019-11-29-00-the-phd-qualitydebate-has-racist-tones/

[23] Ngongalah, L., Niba, R. N., Wepngong, E. N., \& Musisi, J. M. (2018). Research challenges in Africa-an exploratory study on the experiences and opinions of African researchers. bioRxiv, 446328.

[24] O'Regan, N., Ghobadian, A. \& Sims, M. (2006). Fasttracking innovation in manufacturing SMEs. Technovation 26, 251-261.

[25] Odarno, L. (2019). Closing Sub-Saharan Africa's Electricity Access Gap: Why Cities Must Be Part of the Solution. Retrieved from https://www.wri.org/blog 
/2019/08/closing-sub-saharan-africa-electricity-accessgap-why-cities-must-be-part-solution/ [Accessed on 15/01/2020].

[26] Otieno, P. (2015). Africa's housing crisis. Retrieved from https://constructionreviewonline.com/2015/09/africashousing-crisis/ [Accessed on 15/01/2020]

[27] Patra, S. K. (2017). Engineering research in Africa is growing but it's still a patchy picture. Retrieved from https://theconversation.com/engineering-research-inafrica-is-growing-but-its-still-a-patchy-picture-88581/ [Accessed on 15/01/2020].

[28] Pheage, T. (2017). Dying from lack of medicines. Retrieved from https://www.un.org/africarenewal/magazine/december2016-march-2017/dying-lack-medicines/ [Accessed on 15/01/2020].

[29] Shavinina, V. S. (2003). Understanding innovation: Some important issues. London: Elsevier Science.

[30] Smith, A. (1776). An Inquiry into the Nature and Causes of the Wealth of Nations. New York: Modern Library edition.

[31] Thewaterproject.org. (n.d.). Poverty and Water: Poverty in Africa is often caused by a lack of access to clean, safe water and proper sanitation. Retrieved from https://thewaterproject.org/why-water/poverty/ [Accessed on 15/01/2020].

[32] Thomas, J. R., \& Nelson, J. K. (2001). Research methods in physical activity (4th Edition). Albany: Human Kinetics.

[33] Thondhlana, S., Mawere, D. \& Weda, Z. (2011). Factors Affecting Completion of Research Projects by Students: A Study of Three Zimbabwe Open University Regions. Zimbabwe International Journal of Open and Distance Learning, 1(1), 21-28.

[34] Tidd, J., Bessant, J. \& Pavitt, K. (2002). Managing Innovation: Integrating Technological, Market and Organizational Change. 2nd ed., Chichester: Wiley.

[35] Wolpert, J. (2002). Breaking out the innovation box. Harvard Business Review, 80(8), 76-83.

[36] White, D. \& Fortune, J. (2002). Current practice in project management: an empirical study. International Journal of Project Management, 20, 1-11.

[37] White, R. M. (1995). What has engineering research done? Forces Shaping the U.S. Academic Engineering Research Enterprise Washington DC: National Academic Press. 